\title{
Retrieval and Reconsolidation: Toward a Neurobiology of Remembering
}

\author{
Susan J. Sara ${ }^{1}$ \\ Neuromodulation and Cognitive Processes, Institut des Neurosciences, Centre National de la Recherche Scientifique (CNRS) Unité Mixte \\ de Recherche (UMR) 7624, 75005 Paris, France
}

A permanently existing "idea" which makes its appearance before the footlights of consciousness at periodical intervals is as mythological an entity as the Jack of Spades.

William James (1890)

Memory lends itself to study through its retrieval whether it is evaluated by the behavior of a mouse in a swimming pool, a verbal report from a human subject, or inferred from an electrophysiological event. As William James so aptly pointed out, "the only proof of there being retention is that recall actually takes place." (1892). Such a view of memory as remembering is well elaborated in the theoretical reflections of Bergson (1896), in the seminal studies of Bartlett (1932) and later in those of Tulving (Tulving and Thomson 1973) and Craik (1983), who argue, after Bergson, that remembering is an activity similar to perceiving, in the sense that it involves the apprehension and comprehension of contemporary stimuli in the light of past experience.

Although some memory retrieval is likely to occur spontaneously as a result of random fluctuations of patterns of neuronal activity, retrieval is usually brought about as a result of integration of incoming environmental information with the "memory network" driven by that information (Tulving and Thomson 1973). It follows from this that retrieval will lead to the formation of new memories made on the background of a retrieved prior experience. Therefore, it is inconceivable that new memory can be acquired independently of retrieval of past experience, in that it is memory of the past, that organizes and provides meaning to the present perceptual experience. Borrowing Tulving's terminology, new episodic memory, to be remembered in a meaningful way, must be consolidated within a preexisting semantic memory. This analysis does not draw a clear demarcation between consolidation and retrieval processes and in this view, it can be assumed that every retrieval operation should trigger a reconsolidation process (Spear and Mueller 1984). Moreover, decoding or retrieval will change the information content of the "trace" such that memory can be viewed from a neurobiological point of view as an emergent, dynamic, adaptive property of the nervous system.

${ }^{1}$ E-MAIL sjsara@ccr.jussieu.fr; FAX 33144273251.
The theoretical emphasis on memory reactivation and reconsolidation made here raises the issue, as yet ill addressed by neurobiological experiments, of factors that control or modulate these processes. We first review the literature dealing with the neurobiological factors that are involved in the actual retrieval process, a literature that was, until recently, relatively sparse. The advent of noninvasive imaging technology applicable to human studies has, however, awakened interest in this topic and has resulted in a proliferation of studies directly dealing with this aspect of memory function. These will be briefly discussed. The second part of this review deals with recent neurobiological evidence for reconsolidation of memories after their reactivation.

\section{RETRIEVAL}

\section{The Consolidation Hypothesis and its Origins}

Nineteenth century clinical studies of retrograde amnesia after cerebral trauma led Ribot (1882) to formulate the "Loi de Regression," which held that those events experienced immediately before the trauma were the most likely to be forgotten. These and later clinical observations can be considered as the foundation of the consolidation hypothesis, which holds that memories are made after the initial experience, existing initially in a fragile form and strengthened over time, becoming less and less vulnerable to interference. From this hypothesis emerged the prevailing paradigm for the study of brain mechanisms of memory for many years-experimentally induced retrograde amnesia in rodents. The protocol usually used a one trial avoidance task followed by a post-training amnestic treatment at various intervals after the training trial. Treatments effective in inducing amnesia include electroconvulsive shock (ECS), hypoxia, hypothermia, inhibitors of protein synthesis, and various other drugs. The common feature of these diverse insults to the brain lies in their temporal gradient of efficacy

LEARNING \& MEMORY 7:73-84 @ 2000 by Cold Spring Harbor Laboratory Press ISSN1072-0502/00 \$5.00

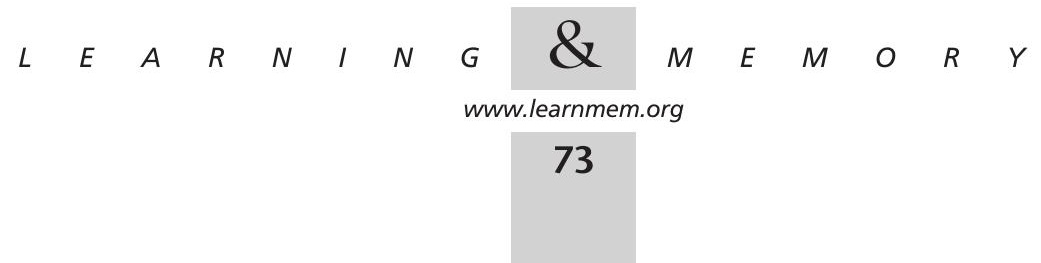


in inducing amnesia. For the most part, the efficacy of the treatment depends on temporal contiguity to the training episode; the shorter the interval between the training and the treatment, the greater the amnestic effect. Time-dependent impunity to these amnestic treatments was taken as evidence that the memory was now in a fixed, consolidated, stable state (McGaugh 1966; Squire and Alvarez 1995).

\section{Retrieval Facilitation \\ After Experimental Amnesia}

A caveat for interpretation of results of experiments within this paradigm came from a series of experiments showing that after amnestic treatments, retrieval of memory could be achieved by exposing rats, right before the retention test, to cues associated with the original training. This was demonstrated in many studies showing recovery from ECS, hypoxia, or other experimentally induced retrograde amnesias. Effective "reminders" included a weak foot shock, exposure to the training context, or a combination of the training context and the foot shock (Lewis et al. 1968; Quartermain et al. 1972; Miller and Springer 1972; Sara 1973; DeVietti and Hopfer 1974; Sara et al. 1975; Gordon and Mowrer 1980). Small doses of analeptic drugs, such as strychnine, amphetamine, or piracetam, when administered before the retention test, also were shown to reverse ECS or hypoxiainduced amnesia, presumably by acting directly on retrieval

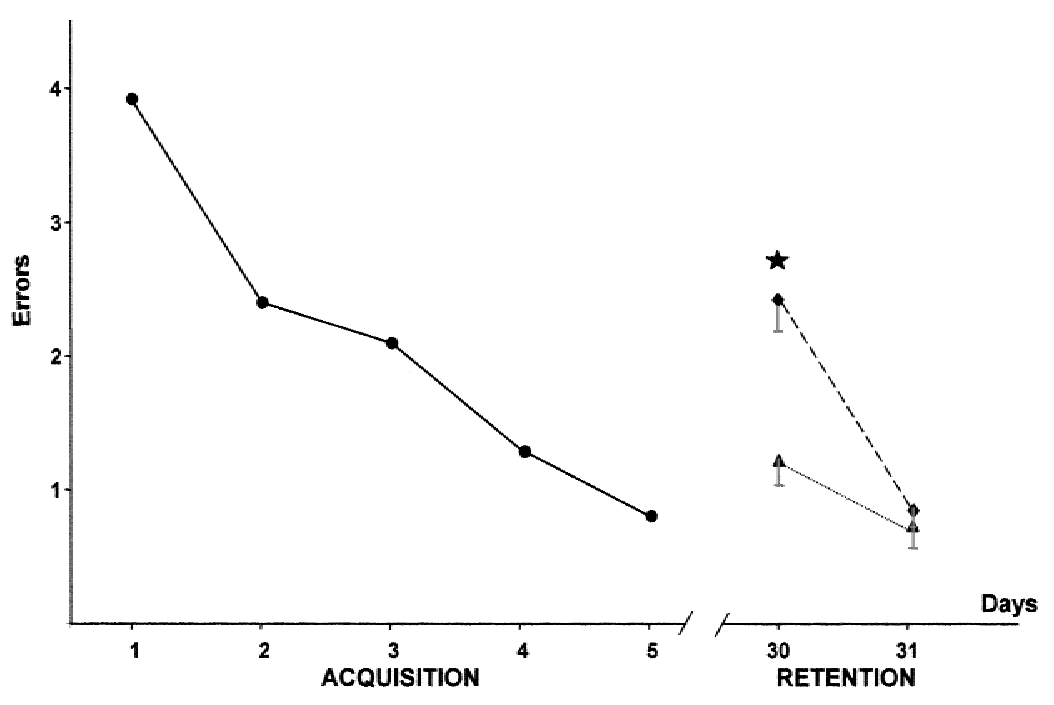

Figure 1 Facilitation of retrieval by a contextual cue reminder before the retention test. (Left) Number of errors at each daily trial during acquisition; (right) retention performance of rats tested 3 weeks after the last training trial. ( ) Control rats habituated to the contextual reminder by exposure to it every day during the 3-week retention interval; $(\boldsymbol{\Lambda})$ reminded rats, presented with the contextual reminder once, just before the retention test. Nonreminded control rats make significantly more errors than at the last training trial and significantly more errors than rats that are exposed to the context for $90 \mathrm{sec}$ before the test. The contextual cue reminder alleviates forgetting and the performance of reminded rats is not different from that of the last training trial (adapted from Deweer et al. 1980). processes (Sara and David-Remacle 1974; Sara and Remacle 1977). A series of important papers by Warrington and Weiskrantz, around the same time, showed that human amnestics could express normal memory performance if they were cued before the retention test. They suggested that at least some forms of amnesia are due to retrieval dysfunction rather than failure to consolidate memories (Weiskrantz 1966; Warrington and Weiskrantz 1970). These observa, reinforced by a strong conceptual framework provided by Spear (1973), encouraged further studies of retrieval in animals.

\section{Memory Retrieval Facilitation After Forgetting: Contextual Cue Reminders}

Memory can be viewed as a "multidimensional conglomerate of attributes" (Spear 1974, p. 56) among which are included both external and endogenous context. The simple passage of time may weaken memories in the sense that they become less readily accessible, less likely to be expressed at retention test. It is well known, however, that behavioral expression of forgetting or retention may be retention test (for review; see Spear 1974). We developed an animal model of "spontaneous forgetting" in which rats trained to run in a six-unit place discrimination maze for food reward showed a reliable retention deficit when tested 3 weeks after training. The rapid acquisition (five single daily trials) is probably the key to this memory deficit over time. Forgetting could be alleviated by pretest "reminders", with timing being a crucial factor in determining the efficacy of the reminder treatment. Rats exposed for 1-2 min to the context in which the learning had taken place made fewer errors than rats placed in a neutral environment before the retention test. The context reminder had to be given immediately before the test; rats reminded $1 \mathrm{hr}$ before the test did not show this facilitation (Deweer et al. 1980; Deweer and Sara 1984).

Pretest exposure to the experimental context in which discriminative avoidance training had taken place also alleviates forgetting. These experiments compared the effectiveness of the contextual cue and the conditioned stimulus (CS) as reminders and found that pretest priming with the CS facilitated performance at short training to test intervals, whereas the contextual cue was only effective after a long retention interval, when control animals showed considerable forgetting (Gisquet-Verrier and Alexinsky 1986; Gisquet-Verrier et al. 1989).

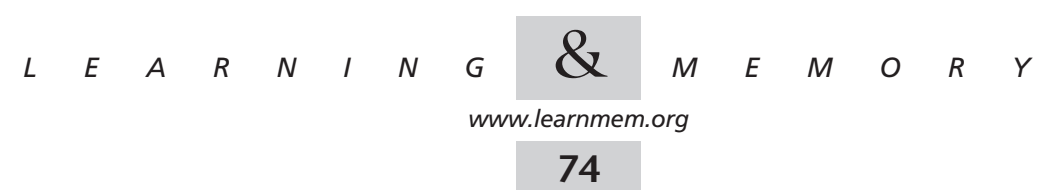




\section{State-Dependent Retrieval}

Closely related to facilitation of memory retrieval by contextual cue reminders is the phenomenon of "state dependent" retrieval. Here the endogenous context, or physiological state of the organism, including neurohumoral and hormonal state, is supposedly incorporated into the conglomerate of memory attributes and exerts control over retrieval of the memory (Spear 1974; Izquierdo 1984). The phenomenon is easily demonstrated using pharmacological manipulation with amphetamine or barbiturates (Overton 1974) or opioids (Bruins Slot and Colpaert 1999). Animals trained with the drug and tested without show poor retention, while those receiving drug treatment before both training and test, show good retention.

Pretest treatment with hormones released during stress, such as adrenocorticotrophic hormone (ACTH) (Mactutus et al. 1980), opioids (Izquierdo 1984), epinephrine (Izquierdo and McGaugh 1987), and vasopressin (Sara et al. 1982; Almedia and Izquierdo 1984) has been shown to effectively reinstate memory for aversive events, both after experimental amnesia and in normal forgetting. A widely accepted interpretation of these results is that the hormone treatment reinstates the internal context of training that then facilitates access to the target memory, in much the same way that an exogenous contextual cue does (see Spear 1974; Riccio and Concannon 1981; McGaugh 1983; Izquierdo 1984).

\section{Pharmacological Facilitation of Retrieval of "Forgotten" Memories}

There are relatively few pharmacological studies of direct effects on memory retrieval. Drugs facilitating retrieval when injected before the retention test include strychnine (Gordon and Spear 1973; Sara and Remacle 1977), cocaine (Rodriguez et al. 1993), nootropic drugs (Sara and DavidRemacle 1974; Sara et al. 1979; Sara, 1980) nicotine (Faiman et al. 1992; Zarrindast et al. 1996), and glucose (Manning et al. 1998). There are reports of vasopressin facilitation of retrieval and the effects appear to be mediated through nicotinic receptors (Faiman et al. 1992).

Amphetamine, a drug with multiple central and peripheral actions, among which include enhancement of release of both dopamine and noradrenaline (NA), facilitated retrieval of the forgotten maze task, when the injection was made before the retention test, 3 weeks after training. The effect was specific to retrieval after a forgetting interval; there was no effect on when it was given before or after acquisition trials (Sara and Deweer 1982). Retrieval of a forgotten conditioned emotional response was facilitated by pretest treatment with amphetamine as well, when the animals were treated just before the retention test (Sara 1984; Quartermain et al. 1988). It is important to note that in none of these experiments was there any evidence of state de- pendency, although this had been reported in several earlier studies (for review, see Overton 1974)

It is noteworthy that those drugs reported to directly facilitate retrieval after experimentally induced amnesia or spontaneous forgetting share the common action of increasing arousal or vigilance, even if by different mechanisms. Further evidence for the importance of arousal in memory retrieval processes comes from experiments in which low level electrical stimulation of the mesencephalic reticular formation (MRF) just before the test alleviated forgetting in the same maze task (Sara et al. 1980). Subsequent experiments indicated that the MRF stimulation-induced increase in arousal alone did not facilitate retrieval; the memory had first to be "primed" or reactivated by exposure to the context in which the training had taken place. Moreover, the effectiveness of the contextual cue reminder was potentiated by concurrent stimulation of the MRF (Dekeyne et al. 1987).

\section{Memory Retrieval and the Noradrenergic System}

Later studies, using the same maze forgetting paradigm, implicated the noradrenergic system, by showing facilitation of retrieval with pretest injection of the $\alpha 2$ receptor antagonist yohimbine (Sara 1985) or the more specific antagonist idazoxan (Sara and Devauges 1989b). Both of these drugs increase firing of the noradrenergic neurons in the locus coeruleus (LC) and increase release of NA from terminals in the forebrain target regions by antagonistic action on inhibitory autoreceptors. It should be noted, however, that these systemic injections of idazoxan cause a peripherally mediated increase in blood pressure (V. Devauges and S.J. Sara, unpubl.), which would result in an increase in cerebral blood flow and could account for cognitive facilitation, independent of effects on the central noradrenergic system. Subsequent studies, however, lent further support for the suggestion that the noradrenergic system mediates contextual cue reminder induced retrieval facilitation. In chronically implanted rats, electrical stimulation of the noradrenergic nucleus locus coeruleus just before the retention test facilitated retrieval in the maze-forgetting paradigm, as illustrated in Figure 2 (Sara and Devauges 1989a). The facilitation was blocked by prior systemic injection of the $\beta$-adrenergic receptor antagonist propranolol (Devauges and Sara 1991).

\section{Neuroanatomical Loci of Retrieval Animal Studies}

Based on a review of the early literature on hippocampal lesions in rats, Hirsh (1974) attempted to provide a unifying theory of hippocampal function, calling the hippocampus the gateway to memory as part of a system mediating contextual retrieval. More than 20 years later a direct test of this proposition was unable to provide supporting evidence.

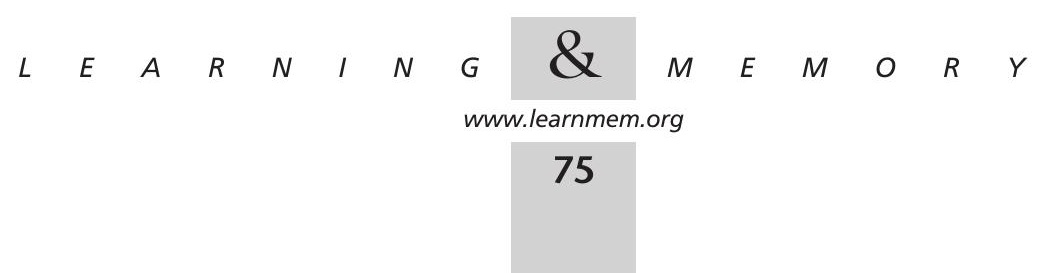




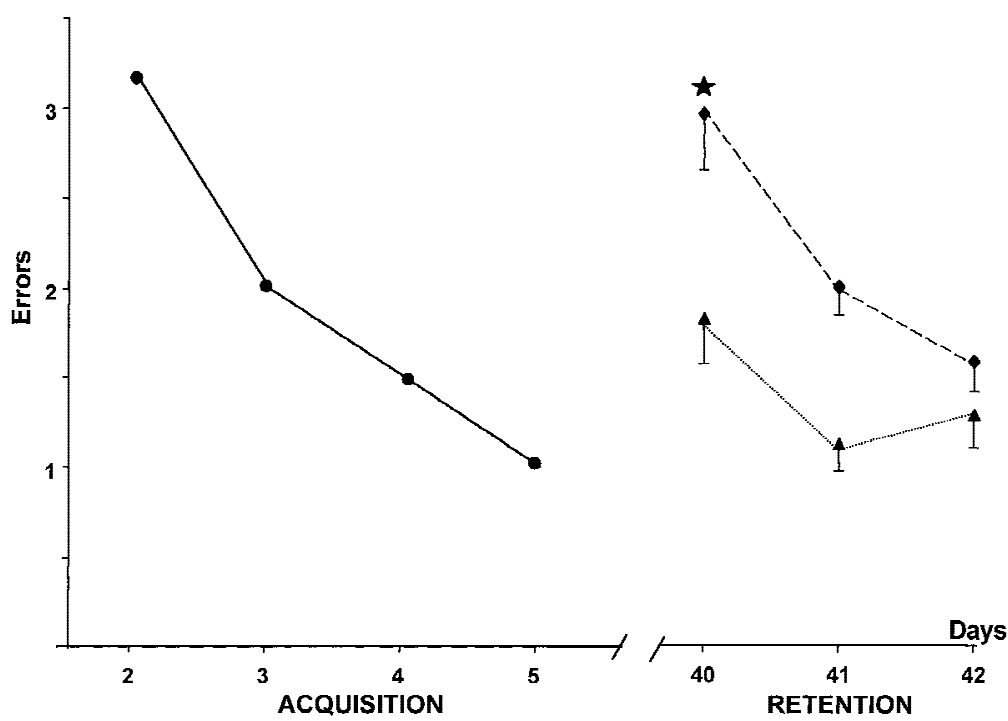

Figure 2 Facilitation of retrieval by electrical stimulation of the locus coeruleus (LC). Training and testing protocol and data presentation as for Fig. 1. Rats were implanted under electrophysiological control with electrodes in the LC. The test was 5 weeks after training; immediately before the test the rat was placed in a wire mesh cage in the experimental room and stimulated with 10 trains of six pulses at $20 \mathrm{~Hz}$, with a 1 -sec intertrain interval, stimulus intensity, $20 \mu \mathrm{A}$. This was repeated once per

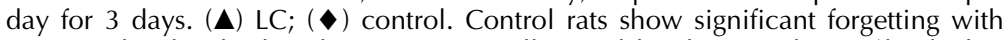
recovery by the third trial. Forgetting is alleviated by the stimulation (for further details, see Sara and Devauges 1989a). Subsequent experiences showed that the retrieval facilitation by stimulation of LC could be blocked by the $\beta$ adrenergic antagonist propranolol (Devauges and Sara 1991).

Discrete lesions of the hippocampus did not prevent the facilitation of memory retrieval by pretest presentation of either the CS or the experimental context (Gisquet-Verrier and Schenk 1994). On the other hand, recent studies using reversible functional inactivation of the dorsal hippocampus have implicated this structure in memory retrieval processes. Local injection of tetrodotoxin impaired retrieval of a passive avoidance response, when the injections were made $1 \mathrm{hr}$ before the retention test (Ambrogi Lorenzini et al. 1996). In another series of studies (Moser and Moser 1998) it was shown that partial inactivation of the hippocampus by local infusion of the GABA agonist muscimol temporarily impaired retrieval of spatial memory, but did not affect new learning. These studies showed that although spatial information can be acquired and retained with only a small number of local ensembles of neurons in the hippocampus, retrieval of spatial information depends on a widely distributed network and requires the integrity of at least $70 \%$ of the dorsal hippocampus. Furthermore, it appears that the integrity of AMPA/kainate receptors within the hippocampus is necessary for retrieval (Riedel et al. 1999), whereas the NMDA receptors are involved only in the encoding, but not retrieval of spatial information (Steele and Morris 1999).

Retrieval in Humans: Functional Imaging

Functional imaging technology is beginning to reveal brain areas specifically engaged during retrieval, and this will undoubtedly prove to be a powerful tool in the future to address this question. Already it has provided some clues to the engagement of particular anatomical regions of the brain in different aspects of the retrieval process. For example, Tulving's studies suggest that during effortful retrieval, the right frontal cortex be activated, whereas the hippocampus is engaged when the retrieved memory is recognized as such (Calabrese et al. 1996). In fact, there is a growing consensus from both positron emission tomography (PET) and magnetic resonance imaging (MRI) studies that the right frontal cortex is selectively engaged during retrieval attempt (Nyberg et al. 1996a; Fletcher et al. 1998; Wagner et al. 1998). Although some attempts are being made to analyze networks using these techniques (Nyberg et al. 1996b), these approaches thus far can only suggest the gross anatomy of regions that show changes in metabolic activity during memory retrieval (for review, see Cabeza and Nyberg 1997). Information concerning dynamics of implicated networks can, for the time being, be best provided by invasive techniques of recording neuronal activity from multiple electrode sites. Understanding at a cellular level will require other in vivo and ex vivo techniques based on well-validated animal models.

\section{Contextual Cue Reminders, Retrieval, and the Truncated Conditioned Reflex}

Although the anatomical studies from both rats and humans implicate specific structures in memory retrieval operations, namely hippocampus and frontal cortex, the prevailing view is that memories are widely distributed in the brain, and that specific information is actually stored in sensory cortices. Retrieval must somehow involve initial activation of relevant intrinsic networks, selection of relevant extrinsic stimuli, and integration of these different sources of information into a meaningful trace. From subjective experience we know that memory retrieval takes time-it may be a matter of milliseconds, but can extend to minutes or more. Retrieval can occur spontaneously, but it can be the fruit of great effort as well. The role of subtle, but significant, environmental stimuli in triggering these processes is intuitively obvious, and has been investigated systematically in animals and humans. Nevertheless, virtually nothing is known about the physiological processes underlying the act of remembering. The initial process must involve some orientation of attention to a particular stimulus or ensemble of stimuli. How those particular stimuli are recognized as "meaningful" or how they can activate the specific distrib-

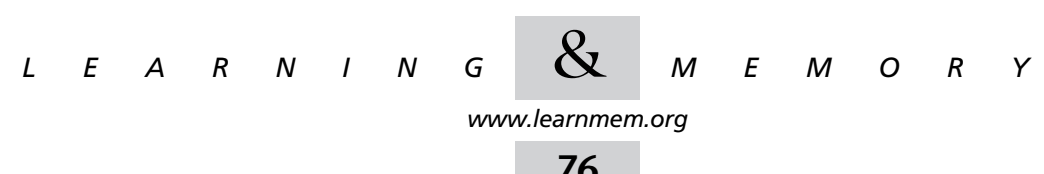


uted network presumed to be the neuronal substrate of the memory still remains unknown.

Formal experiments in the rat, some of which have been described above, have consistently demonstrated the efficacy of exposure to the experiment context in improving memory performance after a long training to test interval, where nonreminded rats show forgetting. Speculatively, this could be the equivalent to the déjà vu phenomenon that we have all experienced. We walk into a room and have an immediate sensation of familiarity, without being able to evoke a particular episodic memory associated with the context. We experience an increase in arousal and attention, and initiate a search for cues or relevant stimuli within the context to facilitate retrieval of the target memory. That operation can take several seconds or minutes or even more before "ecphory" (Tulving and Markowitsch 1997).

The contextual cue reminder may act to facilitate memory in rats in a similar way. The context elicits a conditioned arousal response, which then facilitates brain
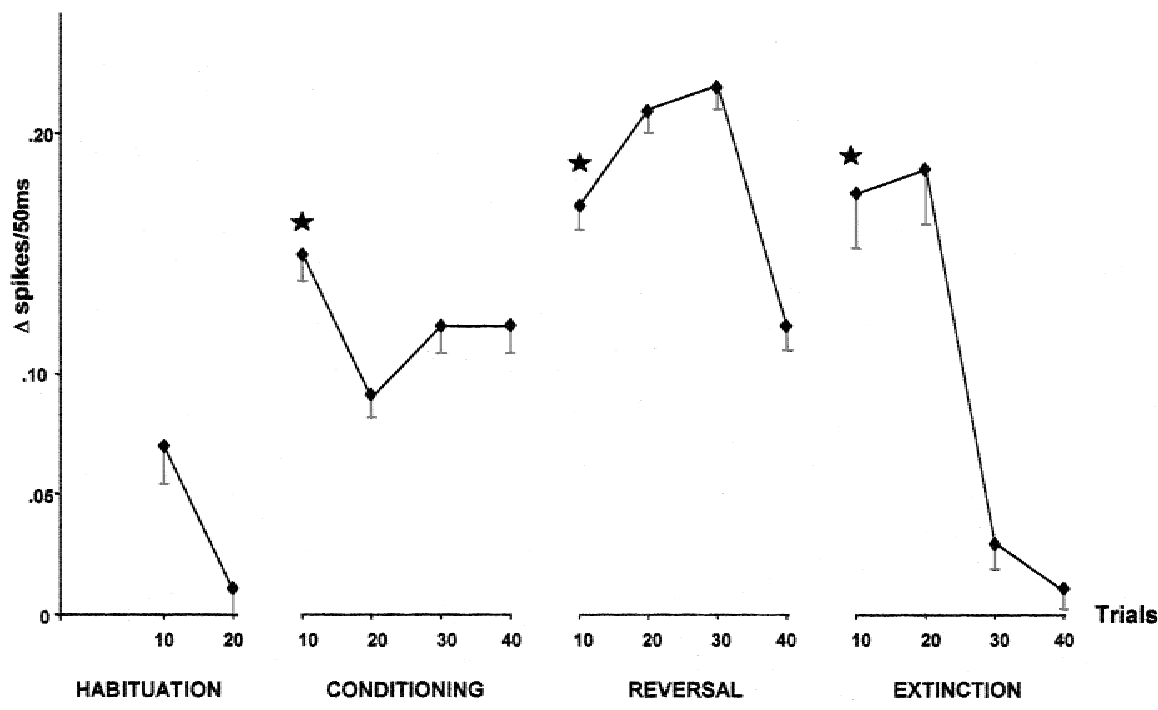

Figure 3 LC unit response to the conditioning context.Rats are trained to discriminate between tones of different frequencies, one of which is associated with a foot shock (CS+) and the other not (CS-). Two seconds before the presentation of either tone, a flashing light comes on and continues for the duration of the tone $(2 \mathrm{sec})$. Each of the tones is contained within the flashing light, which may considered as a context for the CSs. Single unit activity is recorded from a movable microelectrode in the LC during the different phases of the single multitrial session. The session consists of 20 habituation trials where there is no reinforcement, 40 conditioning trials in which the CS+ trials are followed by foot shock, 40 reversal trials where the CS- is now followed by foot shock, and 40 extinction trials where neither CS is followed by foot shock. The average number of spikes per 50-msec bin is calculated for the 4-sec period before the trial and the difference between this value and the average number of spikes per $50 \mathrm{msec}$ bin during the light contextual stimulus is presented in blocks of 10 trials. There is little response to the light during the habituation phase, significant increase at the beginning of conditioning, a further increase at the beginning of reversal, and a further significant increase at the beginning of extinction. The response to the light extinguishes rapidly to zero at the end of the extinction trials. These robust responses to the contextual stimulus are in stark contrast to the LC unit response to the tone CSs. These are more robust when the stimulus is novel, habituate rapidly, and reappear transiently whenever the stimulus-reinforcement contingencies are changed (i.e., under reversal or extinction; Sara and Segal 1991). mechanisms underlying retrieval. Pavlov believed that coractivation was regulated through conditioning and his experimental context, because of its regular association with the reinforcement, comes to elicit a nonspecific conditioned response - an increase in cortical tonus (Sara 1985, 1991). Konorski (1967) later developed this idea, referring to it as the preparatory response and assigning it a major role in the conditioning process. For the present analysis tual cue reminders in facilitating retrieval. The context, which had been associated with the reinforcement during learning, acts as a CS to elicit an arousal response. Such a response could involve activation of multiple peripheral and central mechanisms-the adrenal-pituitary axis, neurons of the MRF, locus coeruleus, and other brainstem neumodulating systems. ally does elicit firing of these neurons during retrieval. Experiments from our laboratory have shown that LC cells do respond vigorously to information about the context in which are embedded the conditioned stimuli (CS+ and CS-), during discriminative conditioning (Sara and Segal 1991; see Fig. 3 for details). It still remains to be demonstrated that LC neurons fire when the animal is exposed to the context in which learning took place, after a long retention interval.

A schematic diagram summarizing the relationship between context and retrieval is provided in Figure 4. In accordance with Kupalov, the experimental context, because of its association with the reinforcement, comes to elicit a conditioned response that includes firing of LC neurons. This would result in release of NA in the forebrain.

There is an extensive literature on postsynaptic effects of NA in sensory pathways, with several investigators suggesting that NA increases signal/noise by inhibiting background neuronal firing while sparing evoked activity (Foote et al. 1975; Waterhouse and Woodward 1980; Hasselmo et al. 1997) or tuning sensory responses by narrowing the receptive field of sensory neurons (Waterhouse et al. 1990;

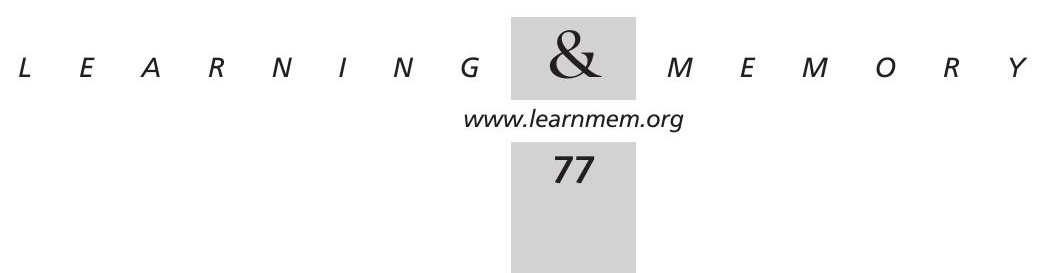




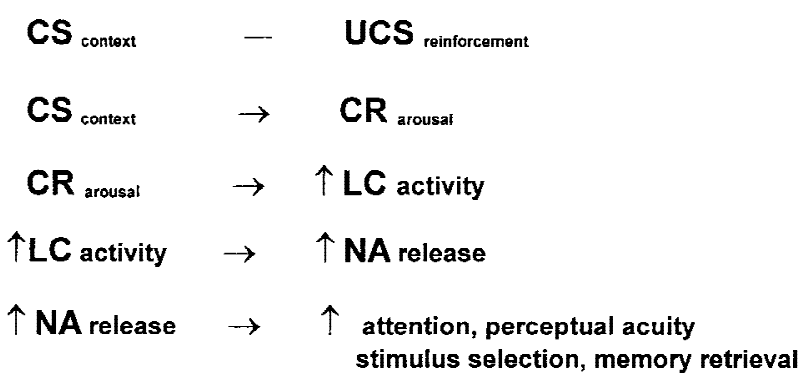

Figure 4 Schematic summary of the hypothesis that the truncated conditioned reflex (CR) mediates the contextual cue reminder effect. The experimental room is the context that is associated over many trials of pretraining and training with the reinforcement such that it becomes a conditioned stimulus for the food reward. The contextual CS elicits a CR, which is an arousal response that may include an array of peripheral and central factors including an increase of firing of LC neurons. The resultant effect of NA on target regions will serve to gate and tune sensory input, orient attention and consequently facilitate retrieval of the target memory.

Manunta and Edeline 1999). Such actions would serve to enhance perceptual acuity. If memory retrieval is intimately related to perceptual processes as we suggested in the introduction, then this action of NA or other neuromodulators could facilitate retrieval by orienting attention, and gating and tuning responses to sensory stimuli (Sara 1985, 1991).

\section{REACTIVATION AND RECONSOLIDATION}

\section{Reactivation and Experimental Amnesia}

Embedded in the extensive literature on experimental amnesia and memory consolidation were several iconoclastic papers representing the work of just three or four laboratories, showing that a temporally graded retrograde amnesia could be obtained for a memory that was reactivated or retrieved just before the amnestic treatment. If the rat, well trained to a specific task and thus having a well-consolidated memory, is exposed to part of the learning environment-usually the reinforcement or a contextual cue-and this is followed by the amnestic treatment, then the animal shows amnesia for the task on a subsequent retention test. This was first demonstrated after reactivation of passive avoidance training followed by ECS (Misanin et al. 1968). This same group later showed that the phenomenon not to be limited to memories forfoot shock after single trial avoidance training. After extensive training in a complex maze task, memory was reactivated by exposure to the start box and the click of the opening of its door (the start box alone was not a sufficient cue). When this was followed by the amnestic agent, ECS, amnesia was obtained (Lewis et al. 1972; Lewis and Bregman 1973). Numerous control procedures assured that the specific cues associated with the original learning were essential to the effect and not merely a reinstatement of an emotional or motivational state, as had been suggested by other investigators (Misanin et al. 1968; Robbins and Meyer 1970). Hypothermia-induced amnesia for a well-trained task was obtained after exposure of the rat to either the unconditioned stimulus (UCS) (foot shock) or the context and UCS, immediately before the amnestic treatment (Mactutus et al. 1979; Richardson et al. 1982). These researchers even found that reactivated memories were more susceptible to the hypothermic treatment than newly acquired memories, in that less cooling was required to obtain amnesia after reactivation. Finally, inhibition of protein synthesis produces amnesia for a well consolidated memory in mice, provided that the memory is reactivated by presentation of the CS before the drug treatment (Judge and Quartermain 1982).

\section{Reactivation and Memory Facilitation}

Reactivated memory is not only vulnerable to amnestic agents, but it can be facilitated by treatments that enhance memory consolidation. Experiments by DeVietti et al. (1977) demonstrated that electrical stimulation of the MRF, which improves memory consolidation when administered within a short time after acquisition, improved memory for a single trial-conditioned fear response in rats when it was applied after memory reactivation and the rat was tested 24 hr later. The shorter the interval between the reactivation and the stimulation, the better the memory enhancement, the temporal gradient of efficacy being quite similar to the postacquisition gradient.

Although of great theoretical and clinical importance, these reactivation studies did not receive the attention that they merited at the time, perhaps because the experimental amnesia paradigm was more or less abandoned with the discovery of long-term potentiation (LTP), which became the prevailing paradigm for memory research in the $1980 \mathrm{~s}$ and 1990s. Nevertheless, the results clearly indicate that it is not necessarily the newness of the memory which determines its lability, but whether it is active or inactive at the time of treatment. A recent series of studies has lent support to this view, showing that both glucose and fructose enhance memory, not only for newly acquired memories, but also for reactivated passive avoidance training, in a doseand time-dependent manner. For the treatment to be effective, it must be given within $30 \mathrm{~min}$ of the reactivation experience, a reminder foot shock (Horne et al. 1997; Rodriguez et al. 1999).

Thus, memories exist in an active state where they are labile and susceptible to disruption by amnestic agents or enhancement by memory modulators, and in an inactive or dormant state during which they are resistant to amnestic brain insults or memory enhancing treatments. In fact, recent results suggest that even the lowly terrestrial slug Limax flavus demonstrates dynamic memory reorganization after reactivation. Hypothermia can induce amnesia for an odor aversion in this species, if it is applied within $1 \mathrm{~min}$

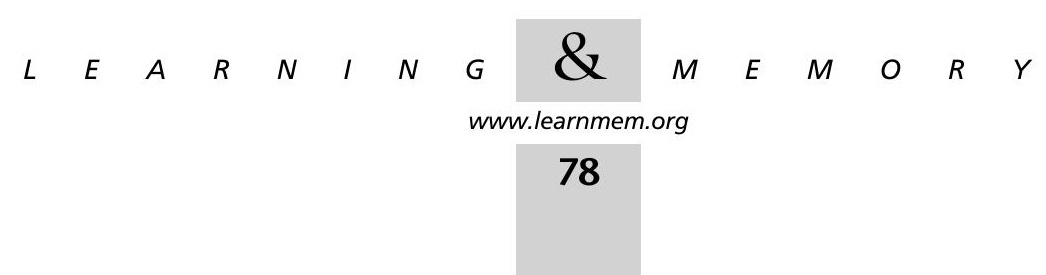


after acquisition or $1 \mathrm{~min}$ after the well-established memory is reactivated by a brief exposure to the carrot conditioned stimulus (Yamada et al. 1992; Sekiguchi et al. 1997).

\section{Memory Reactivation and Consolidation During Sleep}

That a dream is the subjective experience of the brain reprocessing information acquired during the waking state is a compelling idea and has led to much speculation over the years concerning the relationship between sleep and memory (see review chapters in Fishbein 1981). Convincing experimental evidence supporting the hypothesis that memory is further processed during sleep episodes subsequent to learning has accumulated, with early studies showing a spontaneous increase in the rapid eye movement (REM) phase of sleep subsequent to learning (Leconte and Hennevin 1971; Hennevin and Leconte 1977) and amnesia when animals or human subjects are deprived of REM sleep after learning (Fishbein 1970; Fishbein and Gutwein 1977; for review, see Hennevin et al. 1995; also Smith 1985). Spear and Gordon (1981) proposed a conceptual framework for information processing during sleep, suggesting that memories are reactivated, particularly during the REM phase, and it is this active state of memory that allows further processing or reinforcing of the underlying neural circuits in much the same way that reactivated memories can be impaired or improved in wakefulness (see preceding section). Hennevin and her colleagues have provided strong experimental evidence for reactivation during sleep. They showed that very low level electrical stimulation of the MRF that facilitates memory when applied immediately after acquisition or immediately after reactivation also facilitates memory when applied during REM sleep (Hennevin et al. 1989). Using the rationale that, if memory consolidation does occur during sleep that follows learning, then it could be reinforced by reactivating specific circuits related to the learning, a previously learned CS was presented as a reminder during REM sleep. Rats undergoing this reactivation treatment showed better memory when tested in subsequent wakefulness (Hars et al. 1985; Hennevin and Hars 1985). A physiological substrate for the interpretation of this reactivation experiment has been provided by more recent experiments showing that brain structures comprising a circuit involved in the initial learning maintain and express plasticity during REM sleep. Conditioned responses to tone paired with shock during the awake state can be expressed in both the hippocampus and the medial geniculate nucleus during sleep (Hennevin et al. 1993). Conditioned neuronal responses in the amygdala, which probably mediates the affective component of the memory, are likewise elicited by the CS during REM sleep (Hennevin et al. 1998).

There is some evidence that postacquisition information processing occurs in the hippocampus during slow wave sleep (SWS). Pavlides and Winson (1989) reported that particular hippocampal place cells that fired during exploratory behavior were selectively more active during the SWS episode following this behavior. Recording from multiple hippocampal place cells, McNaughton and colleagues have shown that neurons activated together by a behavioral experience during the awake state tend to fire together during subsequent SWS episodes, as revealed by cross correlogram analysis (Wilson and McNaughton 1994; Skaggs and McNaughton 1996; Kudrimoti et al. 1999). They suggest that this correlated activity is the result of a reactivation during sleep, which serves to reinforce a neuronal ensemble representing the memory of the behavioral experience. Buzsaki $(1989,1998)$ has proposed a similar hypothesis concerning memory consolidation occurring during SWS based on observations that postlearning sleep episodes are characterized by an increase in sharp waves or bursting activity in the CA3 region of the hippocampus, which could be reinforcing synapses activated during learning. It is not clear from these analyses what factors determine which ensembles are reactivated during sleep and consequently, how representations are selected for further consolidation.

In the case of Hennevin's experiments, which have included complex maze learning, discriminative avoidance learning and associative conditioning, REM sleep seems to be the important phase for memory processing. In the hippocampal recording studies, where focus has been on neurons associated with spatial information processing, reactivation of ensemble firing appears to occur only during SWS. The discrepancy between the two data sets raises the question of whether different types of information are processed during different brain states. The manipulations during REM sleep-MRF stimulation, reactivation cues-demonstrably facilitate subsequent memory performance in the awake animal, but do not give any indication of the circuits involved. On the other hand, the relation between the increased neuronal ensemble firing of specified neurons and subsequent spatial memory performance expressed at a behavioral level remains to be demonstrated. Buzsaki (1998) has recently suggested that both REM and SWS are critical for memory formation, the function of the former being to update the information input from neocortex to CA3, which is then reinforced during SWS by bursting activity critical for synaptic plasticity and long-term consolidation.

\section{Pharmacological Blockade of Reconsolidation}

A serendipitous finding in our laboratory opened the door to pharmacological investigation of postreactivation reconsolidation. In experiments aimed at assessing the effect of NMDA receptor blockade on the performance of a spatial task, rats were well trained in a radial maze to choose three of eight baited arms, always the same three relative to the spatial configuration of the room cues. Treatment with low doses of the NMDA noncompetitive receptor antagonist

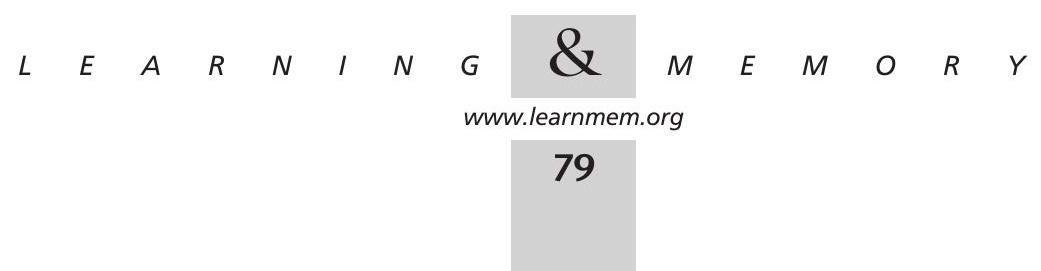


MK-801 had no effect on performance of the task when injected beforehand, but the following day rats expressed an unexpected memory deficit when tested in absence of the drug. Interpreting these results in the light of the nearly forgotten retrograde amnesia-reactivation studies, we hypothesized that the daily trial in the maze reactivated memory, which was then susceptible to disruption. A series of experiments was designed to test specifically the hypothesis that spatial reference memories undergo an NMDA receptor-dependent reconsolidation process after reactivation. Rats were trained to criteria in the radial arm maze with a fixed 3/8-arm pathway. A single trial, which must be errorless, served as the reactivation procedure and pharmacological treatments were administered at varying intervals after this reactivation, to determine the temporal gradient of efficacy of the drug. Using this procedure, we found that blockade of NMDA receptors by MK-801 produces a memory impairment when injections are made within $1 \mathrm{hr}$ of the reactivation and memory is tested $24 \mathrm{hr}$ or $48 \mathrm{hr}$ later (Przybyslawski and Sara 1997). A group of rats receiving the drug treatment outside of the experimental context did not show amnesia. Further evidence for a role of NMDA receptors in a postreactivation reconsolidation process in another species has been provided from studies of passive avoidance memory in the day-old chick. Chicks treated with the receptor antagonist AP5 intracerebroventricularly immediately after being presented with a visual reminder of the training presented transient memory impairment, whereas chicks receiving the drug without the reminder showed no deficit (Summers et al. 1997).

$\beta$-adrenergic antagonists have proved to be effective amnestic agents in the spatial memory paradigm described above, but with a longer temporal gradient than that of NMDA receptor antagonists. Systemic injections of propranolol are effective in inducing memory impairment when given up to $2 \mathrm{hr}$ after the reactivation treatment (Przybyslawski et al. 1999). Trained animals receiving the drug treatment without the reactivation trial did not show amnesia when tested a day or two later. Such amnestic effects are not limited to this spatial reference memory paradigm; we observed similar effects of propranolol after reactivation of a conditioned fear memory. Rats were trained in a passive avoidance task and received the drug treatment right after training or after reactivation by a simple retention test, $48 \mathrm{hr}$ after training. Rats showing perfect retention at the test and then treated with propranolol demonstrated significant amnesia when retested $24 \mathrm{hr}$ later (Przybyslawski et al. 1999). Interestingly, in this experiment the reactivated memory was found to be more vulnerable to the amnestic effects of propranolol that the newly acquired memory, a result reminiscent of that reported by Riccio's group for hypothermia-induced amnesia (see above). The results of the present experiments suggest that memories, be they appetitively motivated spatial memories or based on conditioned fear, require intact $\beta$-receptors to reconsolidate the memory trace after use.

Using intracerebroventricular rather than systemic injections to more accurately control the time and central site of action, we defined a specific time window, 1-2 hr after training, in which $\beta$ receptors play a role in consolidation of newly acquired odor-reward associations. If the receptor antagonist is given immediately after or $5 \mathrm{hr}$ after training, there is no memory impairment (Sara et al. 1999). Recent studies using the radial maze-based spatial memory paradigm described above revealed an extended temporal gradient during which the $\beta$-antagonist is effective, suggesting that this late $\beta$-receptor-dependent phase exists during reconsolidation processes as well (Roullet and Sara 1998).

These pharmacological experiments reinforce the earlier literature reviewed above, showing that reactivated memories are susceptible to interference by a variety of amnestic agents. The results of those early experiments, although they did not extend our knowledge of the neurobiological processes underlying these reconsolidation processes, did encourage the view that memory is dynamic and that new memories are formed on the foundation of reactivated old memories. Our experiments show that postreactivation amnesia can be induced by NMDA receptor blockade for a short period after reactivation (Pryzbyslawski and Sara 1997) and by $\beta$-receptor blockade within a rather precise time window, 1-2 hr after reactivation (Roullet and Sara 1998).

Recently, we have obtained the same pattern of results when the pharmacological treatments were made after initial learning, in a rapidly acquired odor-reward association task. The NMDA receptor antagonist AP5, injected intracerebroventricularly, induced amnesia when injected immediately after training, but not $2 \mathrm{hr}$ after (S. Tronel and S.J. Sara, unpubl.). The $\beta$-receptor antagonist timolol, injected under the same conditions, was effective in producing amnesia at $2 \mathrm{hr}$, but not at $5 \mathrm{~min}, 1 \mathrm{hr}$ or $5 \mathrm{hr}$ after training (Sara et al., unpubl.). The respective intracellular biochemical pathways governed by these receptors and their role in short-term and long-term synaptic plasticity have been described using the LTP model system. Studying the memory characteristics of pharmacologically or genetically modified mice has provided further evidence at a behavioral level of the role of NMDA receptors in the early stages of memory formation and the importance of the cAMP cascade and phosphorylation of cAMP response element binding (CREB) in long-term memory formation (Abeliovich et al, 1993; Bourtchouladze et al. 1994; for reviews, see Mayford et al. 1995; Bailey et al., 1996). Beta-receptors, as a member of the family of receptors positively linked to Gs protein would act by adenyl cyclase to activate this pathway and thereby reinforce long-term memory processes. A schematic diagram of these putative early NMDA receptor dependent and late $\beta$-adrenergic-dependent pathways,

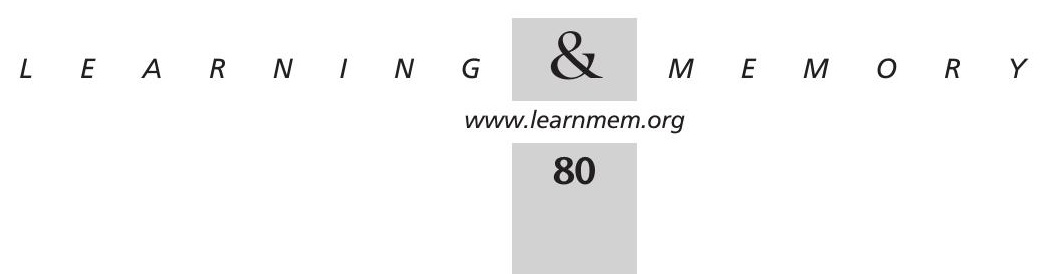




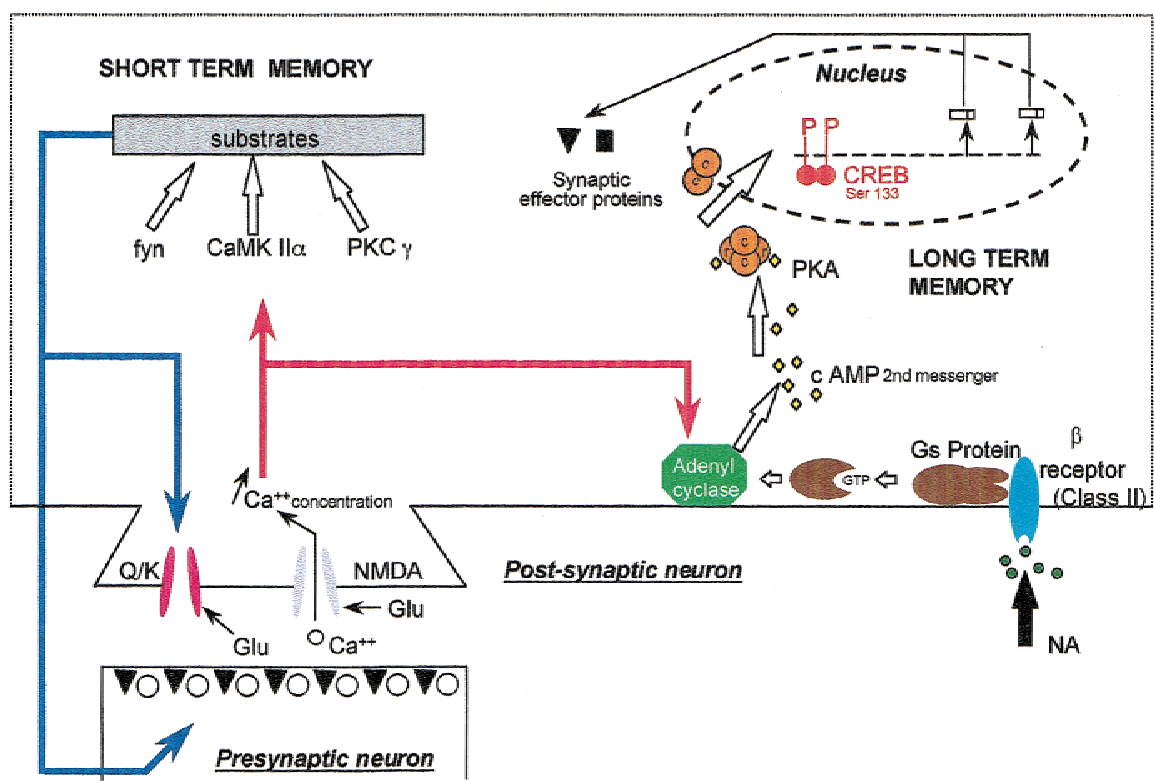

Figure 5 Schematic representation of the intracellular cascades involved in transient and longterm plasticity, initially originally proposed by Mayford et al. (1995) for LTP. (Left) NMDA receptor-governed, calcium-dependent short-term process, leading to generation of a retrograde messenger independent of transcription. (Right) Long-term processes dependent on transcription and de novo protein synthesis. They require activation of the cAMP cascade by adenyl cyclase leading to gene induction by the transcription factor CREB. This can be achieved through intracellular calcium, but also through activation of a family of receptors that are positively linked to $G$ proteins, including $\beta$-noradrenergic receptors. Activation of any or all of the neuromodulatory systems, with consequent release of NA or other neuromodulators would thus promote long-term plasticity underlying memory formation (adapted by Y. Moricard from Mayford et al. 1995).

adapted from Mayford et al. (1995) is summarized in Figure 5.

Although the reactivation studies found in the experimental amnesia literature were performed in absence of any strong neurobiological hypotheses concerning mechanisms, the present results suggest that when a memory is reactivated by stimuli associated with the learning there is a reenactment of at least some of the cellular events that occur during the initial consolidation. To what extent the entire postacquisition cascade of intracellular events, shown in Figure 5, is recapitulated each time a memory is activated and reorganized is probably a function of the age and complexity of the memory and the amount of new information to be integrated into the circuit. It might be a function of the level of arousal, attention, or motivation of the animal at the time of retrieval, as well, since neuromodulatory influences would vary with those parameters.

\section{CONCLUSION AND PERSPECTIVES}

The demonstration of the vulnerability of memory when it is in an active state reinforces the idea that memories, reorganized as a function of new experiences, undergo a reconsolidation process. Recent pharmacological studies indicate that reconsolidation after reactivation recapitulates some of the cellular processes occurring after the initial memory acquisition (Przybyslawski and Sara 1997; Roullet and Sara 1998; S. Tronel and S.J. Sara, unpubl.; Sara et al. 1999). But these studies have not told us anything about the neurobiology of the retrieval process itself. The rapidly developing field of noninvasive functional imaging is providing tools to study brain circuitry involved in retrieval processes at the network level. At the same time genetic technology has advanced to the point where the expression of transgenes can be induced rapidly and reversed in selective regions of the mouse forebrain, providing tools to study cellular mechanisms involved in retrieval and reorganization of memory. Preliminary results confirm that memory storage, memory retrieval, and its reconsolidation share some common processes (Mansuy et al. 1998). We have argued that activation of brainstem neuromodulatory systems, through a conditioned arousal response to the context, will play an essential role in both retrieval and reconsolidation. Release of neuromodulators, particularly NA, will facilitate attention and sensory processing of incoming information during retrieval. The effects of NA and other modulators in triggering intracellular processes upon which stable long-term memory is dependent would promote reconsolidation of the newly reorganized memory. Thus, a high level of attention and arousal at the time of retrieval will play a capital role in reinforcing the memory, since neuromodulatory systems are activated during these behavioral states. This could account for the persistent, vivid memories associated with post traumatic stress disorder (Przybyslawski et al. 1999) and the persistent ability of the drug-taking context to induce craving.

\section{ACKNOWLEDGMENT}

The author thanks Yves Moricard for assistance in preparing the manuscript.

\section{REFERENCES}

Abeliovich, A., R. Paylor, C. Chen, J.J. Kim, J.M. Wehner, and S. Tonegawa. 1993. PKC gamma mutant mice exhibit mild deficits in spatial and contextual learning. Cell 75: 1263-1271.

Almedidia, M.A. and I. Izquierdo. 1984 Effect of intraperitoneal and intracerebroventricular administration of ACTH, epinephrine or betaendorphin on retrieval of an inhibitory avoidance task in rats Behav. Neural Biol. 40: 119-122.

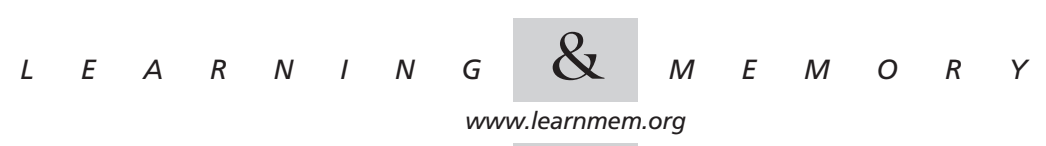


Ambrogi Lorenzini, C., E. Baldi, C. Bucherelli, B. Sacchetti, and G. Tassoni 1996. Role of dorsal hippocampus in acquisition, consolidation and retrieval of rat's passive avoidance response: A tetrodotoxin functional inactivation study. Brain Res. 730: 32-39.

Bailey, C.H., D. Bartsch, and E.R. Kandel. 1996. Toward a molecular definition of long-term memory storage. Proc. Natl. Acad. Sci. 93: $13445-13452$.

Bartlett, F.C. 1932. Remembering. A study in experimental and social psychology. Cambridge University Press, Cambridge, UK.

Bergson, H. 1896. Matière et Mémoire; Presse Universitaire de France, Paris, France

Bourtchuladze, R., B. Frenguelli, J. Blendy, D. Cioffi, G. Schutz, and A.J. Silva. 1994. Deficient long-term memory in mice with a targeted mutation of the cAMP-responsive element-binding protein. Cell 79: 59-68.

Bruins Slot, L.A. and F.C. Colpaert. 1999. Recall rendered dependent on an opiate state. Behav. Neurosci. 113: 337-344.

Buzsaki, G. 1989. Two-stage model of memory trace formation: A role for "noisy" brain states. Neuroscience 31: 551-570.

- 1998. Memory consolidation during sleep: A neurophysiological perspective. J. Sleep Res. 7: 17-23.

Cabeza, R. and L. Nyberg. 1997. Imaging cognition: An empirical review of PET studies with normal subjects. J. Cogn. Neurosci. 9: 1-26.

Calabrese, P., H.J. Markowitsch, H.F. Durwen, H. Widlitzek, M. Haupts, B. Holinka, and W. Gehlen. 1996. Right temporofrontal cortex as critical locus for the ecphory of old episodic memories. J. Neurol. Neurosurg. Psychiatry 61: 304-310.

Craik, F.I.M. 1983. On the transfer of information from temporary to permanent memory. Philos. Trans. R. Soc. Lond. B Biol. Sci. 302: 341-359.

Dekeyne, A., B. Deweer, and S.J. Sara. 1987. Background stimuli as a reminder after spontaneous forgetting: Potentiation by stimulation of the mesencephalic reticular formation. Psychobiology 15: 161-166.

Devauges, V. and S.J. Sara. 1991. Memory retrieval enhancement by locus coeruleus stimulation: Evidence for mediation by beta receptors. Behav. Brain Res. 43: 93-97.

DeVietti,T.L. and T.M. Hopfer. 1974. Complete amnesia induced by ECS and complete recovery of memory following reinstatement treatment. Physiol.Behav. 12 : 599-603.

DeVietti, T.L., G.L. Conger, and B.R. Kirkpatrick. 1977. Comparison of the enhancement gradients of retention obtained with stimulation of the mesencephalic reticular formation after training or memory reactivation. Physiol. Behav. 19: 549-554.

Deweer, B. and S.J. Sara. 1984. Background stimuli as a reminder after spontaneous forgetting: Role of duration of cuing and cuing-test interval. Anim. Learn. Behav. 12: 238-247.

Deweer, B., S.J. Sara, and B. Hars. 1980. Contextual cues and memory retrieval in rats: Alleviation of forgetting by a pretest exposure to background stimuli. Anim. Learn. Behav. 8: 265-272.

Faiman, C.P., G.A. de Erausquin, and C.M. Baratti. 1992. Modulation of memory retrieval by pre-testing vasopressin: Involvement of a central cholinergic nicotinic mechanism. Methods Find. Exp. Clin. Pharmacol. 14: 607-613.

Fishbein, W. 1970. Interference with conversion of memory from short-term to long-term storage by partial sleep deprivation. Commun. Behav. Biol. 5: 171-175.

- 1981. Sleep, dreams and memory. Spectrum, New York, NY.

Fishbein, W. and B. Gutwein. 1977. Paradoxical sleep and memory storage processes. Behav. Biol. 19: 425-464.

Fletcher, P.C., T. Shallice, C.D. Frith, R.S. Frackowiak, and R.J. Dolan. 1998. The functional role of prefrontal cortex in episodic memory. II Retrieval. Brain 121: 1249-1256.

Foote, S., R. Freedman, and A. Oliver. 1975. Effects of putative neurotransmitters on neuronal activity in monkey auditiory cortex. Brain Res. 86: 229-242.

Gisquet-Verrier,P., and T. Alexinsky. 1986. Does contextual change determine long-term forgetting? Anim. Learn. Behav. 14: 349-358.

Gisquet-Verrier, P. and F. Schenk. 1994. Selective hippocampal lesions in rats do not affect retrieval processes promoted by prior cuing with the conditioned stimulus or the context. Psychobiology 22: 289-303.

Gisquet-Verrier, P., A. Dekeyne, and T. Alexinsky. 1989. Differential effects of several retrieval cues over time: Evidence for time-dependent reorganization of memory. Anim. Learn. Behav. 17: 394-408.

Gordon, W.C. and R.R. Mowrer. 1980. An extinction trial as a reminder treatment following electroconvulsive shock. Anim. Learn. Behav. 8: $363-367$.

Gordon, W.C. and N.E. Spear. 1973. The effects of strychnine on recently acquired and reactivated passive avoidance memories. Physiol. Behav 10: 1071-1075.

Hars, B. E. Hennevin, and P. Pasques. 1985. Improvement of learning by cueing during postlearning paradoxical sleep. Behav. Brain Res. 18: $241-250$.

Hasselmo, M.E., C. Linster, M. Patil, D. Ma, and M. Cekic. 1997. Noradrenergic suppression of synaptic transmission may influence cortical signal-to-noise ratio. J. Neurophysiol. 77: 3326-3339.

Hennevin, E. and B. Hars. 1985. Post-learning paradoxical sleep: A critical period when new memory is reactivated? In Brain plasticity, learning and memory (ed. B.E. Will, P. Schmitt, and J.C. Dalrymple-Alford), pp. 193-203. Plenum, New York, NY.

Hennevin, E. and P. Leconte. 1977. Etude des relations entre le sommeil paradoxal et les processus d'acquisition. Physiol. Behav. 18: 307-319.

Hennevin, E., B. Hars, and V. Bloch. 1989. Improvement of learning by mesencephalic reticular stimulation during postlearning paradoxical sleep. Behav. Neural Biol. 51: 291-306.

Hennevin, E. C. Maho, B. Hars, and G. Dutrieux. 1993. Learning-induced plasticity in the medial geniculate nucleus is expressed during paradoxical sleep. Behav. Neurosci. 107: 1018-1030.

Hennevin, E., B. Hars, C. Maho, and V. Bloch. 1995. Processing of learned information in paradoxical sleep: Relevance for memory. Behav. Brain Res. 69: 125-135.

Hennevin, E., C. Maho, and B. Hars. 1998. Neuronal plasticity induced by fear conditioning is expressed during paradoxical sleep: Evidence from simultaneous recording in the lateral amygdala and the medial geniculate in rats. Behav. Neurosci. 112: 839-862.

Hirsh, R. 1974. The hippocampus and contextual retrieval of information from memory: A theory. Behav. Biol. 12: 421-444.

Horne, C.A., W.A. Rodriguez, T.P. Wright, and J.L. Padilla. 1997. Time-dependent effects of fructose on the modulation of a reactivated memory. Prog. Neuropsychopharmacol. Biol. Psychiatry 21: 649-658.

Izquierdo, I. 1984. Endogenous state dependency: Memory depends on the relation between the neurohumoral and hormonal states present after training and at the time of testing. In Neurobiology of learning and memory. (ed. G. Lynch, J.L. McGaugh, and N. Weinberger.), pp. 333-350. Guilford, New York, NY.

Izquierdo, I. and J. McGaugh. 1987. Retention of impairment by pretest epinephrine: Role of state dependency and of endogenous opiod mechanisms. Behavi. Neurosci.101: 778-781.

James, W. 1890. The principles of psychology. Henry Holt, New York, NY.

Judge, M.E. and D. Quartermain. 1982. Alleviation of anisomycin-induced amnesia by pre-test treatment with ly. Pharmacol. Biochem. Behav 16: $463-466$.

Konorski, J. 1967. Integrative activity of the brain. University of Chicago Press, Chicago, IL.

Kudrimoti, H.S., C.A. Barnes, and B.L. McNaughton. 1999. Reactivation of hippocampal cell assemblies: Effects of behavioral state, experience, and EEG dynamics. J. Neurosci. 19: 4090-4101.

Kupalov, P.S. 1961. Some normal and pathological properties of nervous processes in the brain in Pavlovian conference on higher nervous activity. Ann. N.Y. Acad. Sci. 444: 1046-1053.

Leconte, P. and E. Hennevin. 1971. Increase of the duration of paradoxical sleep due to learning in the rat. C.R. Seances Acad. Sci. D. 273: 86-88.

Lewis, D.J. and N.J. Bregman. 1973. Source of cues for cue-dependent amnesia in rats. J. Comp. Physiol. Psychol. 85: 421-426.

Lewis, D., R.R. Miller, and J.R. Misanin. 1968. Control of retrograde amnesia. J. Comp. Physiol. Psychol. 66: 48-52.

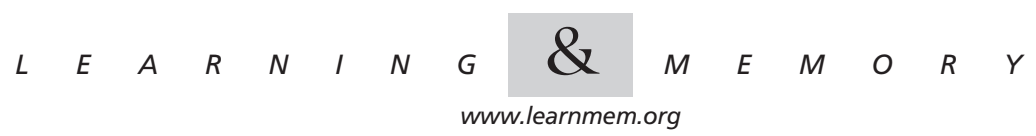


Lewis, D., N.J. Bregman, and J. Mahan. 1972. Cue-dependent amnesia in rats. J. Comp. Physiol. Psychol. 81: 243-247.

Mactutus, C.F., D.C. Riccio, and J.M. Ferek. 1979. Retrograde amnesia for old reactivated memory: Some anomalous characteristics. Science 204: $1319-1320$.

Mactutus, C.F., R.L. Smith, and D.C. Riccio. 1980. Extending the ACTH-induced memory reactiviation in an amestic paradigm. Physiol. and Behav. 24: 541-546.

Manning, C.A., W.S. Stone, D.L. Korol, and P.E. Gold. 1998. Glucose enhancement of 24-h memory retrieval in healthy elderly humans. Behav. Brain Res. 93: 71-76.

Mansuy, I.M., D.G. Winder, T.M. Moallem, M. Osman, M. Mayford, R.D. Hawkins, and E.R. Kandel. 1998. Inducible and reversible gene expression with the rtTA system for the study of memory. Neuron 21: $257-265$

Manunta,Y. and J.-M. Edeline. 1999. Effects of noradrenaline on frequency tuning of auditory cortex neurons during wakefulness and slow-wave sleep. Eur. J. Neurosci. 11: 1-17.

Mayford, M., T. Abel, and E.R. Kandel. 1995. Transgenic approaches to cognition. Curr. Opin. Neurobiol. 5: 141-148

McGaugh, J.L. 1966. Time dependent processes in memory storage. Science 153: 1351-1358.

. 1983. Hormonal influences on memory. Ann. Rev. of Psychol. 34: 297-323.

Miller, R.R. and A.D. Springer. 1972. Induced recovery of memory in rats following electroconvulsive shock. Physiol. Behav. 8: 645-651.

Misanin, J.R., R.R. Miller, and D.J. Lewis. 1968. Retrograde amnesia produced by electroconvulsive shock after reactivation of consolidated memory trace. Science 160: 554-555.

Moser, M.B. and E.I. Moser. 1998. Distributed encoding and retrieval of spatial memory in the hippocampus. J. Neurosci. 18: 7535-7542.

Nyberg, L., A.R. McIntosh, S. Houle, L.G. Nilsson, and E. Tulving. 1996 a. Activation of medial temporal structures during episodic memory retrieval. Nature 380: $715-717$

Nyberg, L., A.R. McIntosh, R. Cabeza, L.G. Nilsson, S. Houle, R. Habib, and E. Tulving. 1996b. Network analysis of positron emission tomography regional blood flow data: Ensemble inhibition during episodic memory retrieval. J. Neurosci. 16: 3753-3759.

Overton, D.A. 1974. Experimental methods for the study of state-dependent learning. Fed. Proc. 33: 1800-1813.

Pavlides, C. and J. Winson. 1989. Influences of hippocampal place cell firing in the awake state on the activity of these cells during subsequent sleep episodes. J. Neurosci. 8: 2907-2918.

Przybyslawski, J. and S.J. Sara. 1997. Reconsolidation of memory after its reactivation. Behav. Brain Res. 84: 241-246.

Przybyslawski, J., P. Roullet, and S.J. Sara. 1999. Attentuation of emotional and nonemotional memories after their reactivation: Role of beta adrenergic receptors. J. Neurosci. 19: 6623-6628.

Quartermain, D., B. McEwen, and E. Azmita. 1972. Recovery of memory following amnesia in the rat and mouse. J. Comp. Physiol. Psychol. 79: 360-379.

Quartermain, D., M.E. Judge, and H. Jung. 1988. Amphetamine enhances retrieval following diverse sources of forgetting. Physiol. Behav. 43: 239-241.

Ribot, T. 1882. Diseases of memory. Appleton-Century Crofts, New York, NY.

Riccio, D.C. and J.T. Concannon. 1981. ACTH and the reminder phenomenon. In Endogenous peptide and learning and memory processes (ed. A. Levy), pp. 117-142. Academic Press, New York, NY.

Richardson, R., D.C. Riccio, and H. Mowrey. 1982. Retrograde amnesia for previously acquired Pavlovian conditioning: UCS exposure as a reactivation treatment. Physiol. Psychol. 10: 384-390.

Riedel, G., J. Micheau, A.G.M. Lam, E.v.L. Roloff, S.J. Marin, H. Bridge, L. deHoz, B. Poeschel, J. McCulloch, and R.G.M. Morris. 1999. Reversible neural inactiviation reveals hippocampal participation in several memory processes. Nature Neurosci. 2: 898-905.

Robbins, M.J. and D.R. Meyer. 1970. Motivational control of retrograde amnesia. J. Exp. Psychol. 84: 220-225.
Rodriguez, W.A., S.B. Rodriguez, M.Y. Phillips, and J.L. Martinez, Jr. 1993 Post-reactivation cocaine administration facilitates later acquisition of an avoidance response in rats. Behav. Brain Res. 59: 125-129.

Rodriguez, W.A., C.A. Horne, and J.L. Padilla. 1999 Effects of glucose and fructose on recently reactivated and recently acquired memories. Prog. Neuropsychopharmacol. Biol. Psychiatry 23: 1285-1317.

Roullet, P., and S.J. Sara. 1998. Consolidation of memory after its reactivation: Involvement of beta noradrenergic receptors in the late phase. Neural Plas. 6: 63-68.

Sara, S.J. 1973. Recovery from hypoxia and ECS induced amnesia after a single exposure to the training environment. Physiol. Behav. 9: 85-89.

- 1980. Memory retrieval deficits: Alleviation by etiracetam, a nootropic drug. Psychopharmacology 68: 235-241.

- 1984. Forgetting of a conditioned emotional response and its alleviation by pretest amphetamine. Physiol. Psychol. 12: 17-22.

- 1985. Noradrenergic modulation of selective attention: its role in memory retrieval. Ann. N.Y. Acad. Sci. 444: 178-93.

- 1991. Noradrenaline and memory: Neuromodulatory influences on retrieval. In Memory: Neurochemical and abnormal perspectives (ed. J. Weiman and J. Hunter), pp. 105-128. Harwood, Chur, Switzerland

Sara, S.J. and M. David-Remacle. 1974. Recovery from electroconvulsive shock-induced amnesia by exposure to the training environment: Pharmacological enhancement by piracetam. Psychopharmacologia 36: 59-66.

Sara, S. and V. Devauges. 1989a. Priming stimulation of locus coeruleus facilitates memory retrieval in the rat. Brain Res. 438: 401-411.

. 1989b. Idazoxan, an alpha2 antagonist, facilitates memory retrieval in the rat. Behav. Neural Biol. 51: 401-411.

Sara, S.J. and B. Deweer. 1982. Memory retrieval enhanced by amphetamine after a long retention interval. Behav. Neural Biol. 36: $146-160$.

Sara, S.J. and D. Lefevre. 1973. A reexamination of the role of familiarization (FAM) in retrograde amnesia. J. Comp. Physiol. Psychol. 84: 361-364.

Sara, S.J. and J.F. Remacle. 1977. Strychnine-induced passive avoidance facilitation after electroconvulsive shock or undertraining: A retrieval effect. Behav. Biol. 19: 465-475.

Sara, S.J. and Segal. M. 1991. Plasticity of sensory responses of locus coeruleus neurons in the behaving rat: Implications for cognition. Prog. Brain. Res. 88: 571-585.

Sara, S.J., M. David-Remacle. and D. Lefevre. 1975. Passive avoidance behavior in rats after electroconvulsive shock: Facilitative effect of response retardation. J. Comp Physiol. Psychol. 89: 489-497.

Sara, S.J., M. David-Remacle, M. Weyers, and C. Giurgea. 1979. Piracetam facilitates retrieval but does not impair extinction of bar-pressing in rats. Psychopharmacology (Berl) 61: 71-75.

Sara, S.J., B. Deweer, and B. Hars. 1980. Reticular stimulation facilitates retrieval of a "forgotten" maze habit. Neurosci. Lett. 18: 211-217.

Sara, S.J., J. Barnett, and P. Toussaint. 1982 Vasopressin accelerates appetitive discrimination learning and impairs its retrieval. Behav Processes 7: 157-167.

Sara, S.J., P. Roullet, and J. Przybyslawski. 1999. Consolidation of memory for odor-reward association: Beta-adrenergic receptor involvement in the late phase. Learn. Mem. 6: 88-96.

Sekiguchi, T., A. Yamada, and H. Suzuki. 1997. Reactivation-dependent changes in memory states in the terrestrial slug Limax flavus. Learn. Mem. 4: 356-364.

Skaggs, W. and B. McNaughton. 1996. Replay of neuronal firing sequences in rat hippocampus during sleep following spatial experience. Science 271: $1870-1873$

Smith, C. 1985. Sleep states and learning: A review of the animal literature. Neurosci. Biobehav. Rev. 9: 157-168.

Spear, N.E. 1973. Retrieval of memory in animals. Psychol. Rev. 80: $163-194$.

. 1974. The processing of memories: Forgetting and retention. L. Erlbaum Associates, Hillsdale, NJ

Spear, N.E. and W.C. Gordon. 1981. Sleep, dreaming, and the retrieval of

\section{……‥}


memories. In Sleep, dreams, and memory (ed. W. Fishbein), pp. 183-203 Spectrum Publications, New York, NY.

Spear, N.E. and C.W. Mueller. 1984. Consolidation as a function of retrieval. In Memory consolidation: Psychobiology of cognition (ed. H. Weingartner and E.S. Parker), pp. 111-147. Lawrence Erlbaum Associates ,Hillsdale, NJ.

Squire, L.R. and P. Alvarez. 1995. Retrograde amnesia and memory consolidation: A neurobiological perspective. Curr. Opin. Neurobiol. 5: 169-177.

Steele, R.J. and R.G.M. Morris. 1999. Delay-dependent impairment of a matching to place task with chronic intrahippocampal infusion of the NMDA antagonist D-AP5. Hippocampus 9: 118-136.

Summers, M.J., S.F. Crowe, and K.T. Ng. 1997. Administration of DL-2-amino-5-phosphonovaleric acid (AP5) induces transient inhibition of reminder-activated memory retrieval in day-old chicks. Brain Res. Cogn. Brain Res. 5: 311-321.

Tulving, E. and H.J. Markowitsch. 1997. Memory beyond the hippocampus. Curr. Opin. Neurobiol. 7: 209-216.

Tulving, E. and D. Thomson. 1973. Encoding specificity and retrieval processes in episodic memory. Psychol. Rev. 80: 352-372.

Wagner, A.D., J.E. Desmond, G.H. Glover, and J.D. Gabrieli. 1998.
Prefrontal cortex and recognition memory. Functional MRI evidence for context-dependent retrieval processes. Brain 121: 1985-2002.

Warrington, E. and L. Weiskrantz. 1970. Amnesic syndrome: Consolidation or retrieval. Nature 228: 628-630.

Waterhouse, B.D. and D. Woodward. 1980. Interaction of norepinephrine with cerebrocortical activity evoked by stimulation of somatosensory afferent pathways in the rat. Exp. Neurol. 67: 11-34.

Waterhouse, B.D., S.A. Azizi, R.A. Burne, and D.J. Woodward. 1990. Modulation of rat cortical area 17 neuronal responses to moving visual stimuli during norepinephrine and serotonin microiontophoresis. Brain Res. 514: 276-292.

Weiskrantz, L. 1966. Experimental studies of amnesia. In Amnesia (ed. C. Whitty and O. Zangwill ), pp. 1-31.Butterworths, London, UK.

Wilson, M. and B. McNaughton. 1994. Reactivation of hippocampal ensemble memories during sleep. Science 265: 676-679.

Yamada, A., T. Sekiguchi, H. Suzuki, and A. Mizukami. 1992. Behavioral analysis of internal memory states using cooling-induced retrograde amnesia in Limax flavus. J. Neurosci. 12: 729-735.

Zarrindast, M.R., M. Sadegh, and B. Shafaghi. 1996. Effects of nicotine on memory retrieval in mice. Eur. J. Pharmacol. 295: 1-6. 


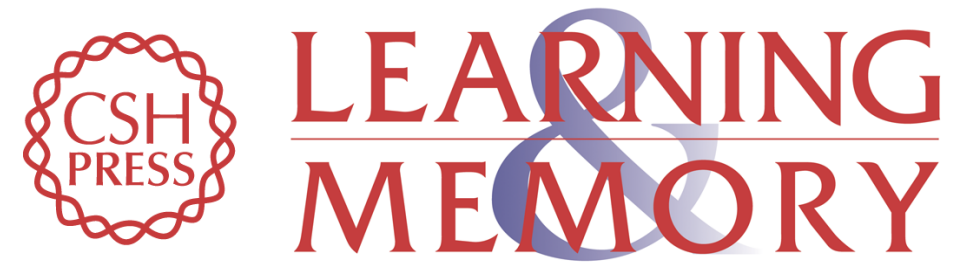

\section{Retrieval and Reconsolidation: Toward a Neurobiology of Remembering}

Susan J. Sara

Learn. Mem. 2000, 7:

Access the most recent version at doi:10.1101//m.7.2.73

References This article cites 92 articles, 15 of which can be accessed free at:

http://learnmem.cshlp.org/content/7/2/73.full.html\#ref-list-1

License

Email Alerting Receive free email alerts when new articles cite this article - sign up in the box at the Service top right corner of the article or click here. 